\title{
REVIEW ON DIAGNOSTIC REFERENCE LEVELS (DRLS) FOR ADULT PATIENTS UNDERGOING CHEST AND ABDOMEN COMPUTED TOMOGRAPHY SCAN IN NORTHERN NIGERIA
}

\author{
Buhari Maidamma $^{1 *}$ and Buhari Samaila ${ }^{2}$ \\ ${ }^{1}$ Department of Physics, Government Day Secondary School Tambuwal, P.M.B. 72, Sokoto, \\ Nigeria. \\ *Corresponding Author Email: buharizimber@gmail.com \\ ${ }^{2}$ Department of physics with electronics, Federal University Birnin Kebbi, P.M.B. 1157 \\ Kebbi, Nigeria. Email: kawara002@gmail.com
}

Cite this article:

Buhari M., Buhari S. (2021), Review on Diagnostic Reference Levels (DRLs) for Adult Patients Undergoing Chest and Abdomen Computed Tomography Scan in Northern Nigeria. African Journal of Environment and Natural Science Research 4(2), 83-90. DOI: 10.52589/AJENSRIMDC9RXI.

\section{Manuscript History}

Received: 20 April 2021

Accepted: 13 May 2021

Published: 21 May 2021

Copyright $\odot 2020$ The Author(s). This is an Open Access article distributed under the terms of Creative Commons AttributionNonCommercial-NoDerivatives 4.0 International (CC BY-NC-ND 4.0 ), which permits anyone to share, use, reproduce and redistribute in any medium, provided the original author and source are credited.
ABSTRACT: Computed tomography $(C T)$ scan procedure has become a higher radiation dose that contributes to all medical $x$ ray procedures in the radiological department. Many researches in the world suggested that computed tomography presents a small fraction (5\%) of the total procedures performed but contributes $34 \%$ of annual radiation doses in all medical $x$-ray procedures. Likewise, other investigations reported that computed tomography presents $17 \%$ of the total number of procedures performed worldwide but contributes $49 \%$ of the annual collective doses in all medical $x$-ray procedures. Therefore, the aim of this review is to provide a diagnostic reference level for adults that undergo chest and abdomen CT scan examinations in northern Nigeria, using the research for this region and comparing with international values to see if better optimization protocol is being practiced, since diagnostic reference levels are part of the ways of optimizing a dose in CT procedure. Based on this review, the results obtained for DRLs for the chest are $17.25 \mathrm{mGy}$ for CTDIvol and $735 \mathrm{mGy} . \mathrm{cm}$ for $D L P$, while the results for the abdomen are $19.25 \mathrm{mGy}$ and $1670.75 \mathrm{mGy} . \mathrm{cm}$ for CTDIvol and DLP respectively. Therefore, all the DRLs' values reviewed are higher than the international values compared except CTDIvol of ICRP 2007 publications. There is an urgent need for an upgrade in CT technology. Optimization of protocols, including exposure and technical parameter selection, should help reduce dose variations in the northern part of Nigeria.

KEYWORDS: DRLs, CT Scan, CTDIvol and DLP 


\section{INTRODUCTION}

Diagnostic reference levels (DRLs) are reference dose levels in medical radio diagnostic practices for typical examinations of groups of standard-sized patients or a standard phantom, and broadly defined types of equipment. These levels are not expected to be exceeded for standard procedures when good and normal practice regarding diagnostic and technical performance is applied (European Commission, 1999). The rationale for setting national diagnostic reference level (NDRL), as stated in an International Atomic Energy Agency (IAEA) document termed Radiation Protection in Patients, emphasized the need for optimization i.e. to keep all CT doses as low as reasonably achievable within clinical ranges, since surveys of CT dose estimates have shown significant variations in practice for the same patient categories in age and size, that have undergone identical types of examinations. The importance of setting diagnostic reference levels (DRLs) cannot be over emphasized; however, it is relevant to know that diagnostic reference levels (DRLs) are not universal but specific to a country. Because of equipment and personnel training, diagnostic reference levels (DRLs) established for one country (with different CT practice and technology) may not be completely relevant to another country's circumstances (Ogbole \& Obed, 2014 and Olowokere et al., 2012). Iterative reconstruction which is an advancement in computed tomography CT technology must also be considered when setting diagnostic reference level (DRL) or comparing one practice to another. Establishing diagnostic reference levels (DRLs) alone does not guarantee long term optimization of doses. Doses must be reviewed from time to time since diagnostic reference levels (DRLs) doses are dynamic values that change overtime with changes in technology (NCRP, report 172).

The development of computed tomography (CT) in the early 1970s revolutionized medical radiology. For the first time, physicians were able to obtain high-quality tomographic (crosssectional) images of internal structures of the body. Over the following 10 years, 18 manufacturers competed for the exploding world CT market. Technical sophistication increased drastically, and even today, CT continues to mature with new capabilities being researched and developed (Cunningham, 2000). Because of the high doses involved in CT examinations relative to the majority of diagnostic radiological examinations, the potential risk to the sensitive organs is considered to be high. Hence, it is useful to be able to calculate the dose from potentially high dose examinations before they are carried out. A computer model was developed to assist in routine calculation of doses during CT examinations. This model could also be used to provide information for routine patient dose estimation, as well as allow different protocols to be evaluated prior to the examination (Garba, 2014).

The concept of the diagnostic reference level (DRL), as a tool to identify situations where patient doses are unusually high and in most urgent need of reduction, was therefore adopted by the International Commission on Radiological Protection in ICRP publications 60 and 73, and by the European Directive 97/43 Euratom (ICRP, 1991; Drouet, 2007). The objective of a diagnostic reference level is to help avoid radiation dose to the patient that does not contribute to the clinical purpose of a medical $\mathrm{x}$-ray imaging task. This is accomplished by comparison between the numerical value of the diagnostic reference level derived from relevant regional, national, or local data and the mean or other appropriate value observed in practice, for a suitable reference group of patients or a suitable reference phantom (ICPR, 2001). The guidelines for establishing DRLs as mentioned by European Commission are as follows (Idris, 2014): 
- DRLs for diagnostic radiology should be based on doses measured in various types of hospitals, clinics and practices, and not only in well-equipped hospitals.

- As mentioned before, because patients and the information required differ widely, DRLs are only applicable to standard procedures, standard phantoms or groups of standard-sized patients, and for specific groups of children distinguished by age, size and weight.

- DRLs can be assessed using entrance surface doses, measured with TLD fixed on the patient's body, or the DAP (Gycm2).

- For CT, the weighted CT dose index $\left(\mathrm{CTDI}_{\mathrm{v}}\right)$ and the dose length product (DLP) are suitable quantities to be used as DRLs.

- DRLs are particularly useful for more common examinations or examinations which may involve high doses or are frequently performed.

- When setting DRLs for procedures performed with digital systems, it is important to remember that the level of image quality can be selected by the user or automatically set by an X-ray system.

- A minimum of twenty (20) patients could be considered per body examination (Idris, 2014).

\section{METHODOLOGY}

This review encompassed the research papers based on prospective and retrospective studies done by many scholars and researchers in northern Nigeria. This study adopted a prospective and retrospective quantitative methodology and cross-sectional research design to determine the diagnostic reference level for adult chest and abdomen, for patients undergoing computed tomography CT scan in northern Nigeria. A quantitative design spreadsheet was used to record the individual data by the researchers in northern Nigeria. The study involved the use of numerical data and was conducted retrospectively to ensure more reliable and valid data. Based on the guidelines stipulated in the literature, the data could be obtained either from researchers in the region or subregion and compared with the other international countries.

\section{Data Analysis}

The data (exposure parameters) obtained from different research articles include: Computed Tomography Dose Index Volume (CTDIvol) and Dose Length Product (DLP). The data were analyzed using recommended SPSS software to provide answers to the research problems of this review. The two statistical methods employed for the analysis of this data are descriptive and inferential analysis. The descriptive analysis was used to summarize the data for this review. It was used to give a description of the data by determining the measure of location (mean) and expressing its variability (standard deviation). Inferential statistical analysis was employed to measure the significance (whether any difference between the researchers is due to chance or a real effect of their results). It was represented using $75 \%$ quartile and this was used to estimate the standard diagnostic reference level (DRL) in the region. 
Data was analyzed using SPSS statistical software. The mean, standard deviation and third quartile values at $25 \%$ and $75 \%$ confidence intervals were used. Comparison was made between the researcher's dose values and reported data from the European countries where there are established diagnostic reference levels (DRLs).

\section{Overview Summary of the result and Discussion}

The results of various research articles by different scholars in the northern part of Nigeria were summarized in tables 1 and 2 for chest and abdomen respectively.

Table 1: Established DRLs for Chest by the Literature Review

\begin{tabular}{|l|l|l|l|l|l|l|l|}
\hline $\begin{array}{l}\text { S/ } \\
\text { no }\end{array}$ & $\begin{array}{l}\text { Centre } \\
\text { Number } \\
\text { Used }\end{array}$ & $\begin{array}{l}\text { Number of } \\
\text { Patients } \\
\text { Used }\end{array}$ & Methodology & CTDI & DLP & Location & Reference \\
\hline 1 & 4 & 226 & $\begin{array}{l}\text { Prospective } \\
\text { Study }\end{array}$ & 10 & 407 & NC & Kabir, 2015 \\
\hline 2 & 2 & 180 & $\begin{array}{l}\text { Prospective } \\
\text { Study }\end{array}$ & 18 & 659 & NE & Joseph et al., 2017 \\
\hline 3 & 3 & 131 & $\begin{array}{l}\text { Retrospective } \\
\text { Study }\end{array}$ & 9.9 & 663 & NW & $\begin{array}{l}\text { Abdullahi et al., } \\
\text { 2019 }\end{array}$ \\
\hline 4 & 2 & 171 & $\begin{array}{l}\text { Retrospective } \\
\text { Study }\end{array}$ & 17 & 735 & NC & $\begin{array}{l}\text { Mary-ann al., } \\
\text { 2018 }\end{array}$ \\
\hline 5 & 40 & NA & $\begin{array}{l}\text { Retrospective } \\
\text { Study }\end{array}$ & 17 & 735 & NORTH & Ernest et al., 2018 \\
\hline 6 & 4 & 226 & $\begin{array}{l}\text { Retrospective } \\
\text { Study }\end{array}$ & 12 & 407 & NC & Kabir et al., 2016 \\
\hline
\end{tabular}

Table 2: Established DRLs for Abdomen by the Literature Review

\begin{tabular}{|l|l|l|l|l|l|l|l|}
\hline $\begin{array}{l}\text { S/ } \\
\text { no }\end{array}$ & $\begin{array}{l}\text { Centre } \\
\text { Number } \\
\text { Used }\end{array}$ & $\begin{array}{l}\text { Number of } \\
\text { Patients } \\
\text { Used }\end{array}$ & Methodology & CTDI & DLP & Location & Reference \\
\hline 1 & 4 & 226 & $\begin{array}{l}\text { Prospective } \\
\text { Study }\end{array}$ & 15 & 757 & NC & Kabir, 2015 \\
\hline 2 & 2 & 180 & $\begin{array}{l}\text { Prospective } \\
\text { Study }\end{array}$ & 19 & 1290 & NE & $\begin{array}{l}\text { Joseph } \text { et al., } \\
\text { 2017 }\end{array}$ \\
\hline 3 & 3 & 131 & $\begin{array}{l}\text { Retrospective } \\
\text { Study }\end{array}$ & 14 & 1397 & NW & $\begin{array}{l}\text { Abdullahi } \text { et al., } \\
2019\end{array}$ \\
\hline 4 & 2 & 171 & $\begin{array}{l}\text { Retrospective } \\
\text { Student }\end{array}$ & 20 & 1486 & NC & $\begin{array}{l}\text { Mary-ann } \text { et al., } \\
\text { 2018 }\end{array}$ \\
\hline 5 & 1 & 100 & $\begin{array}{l}\text { Retrospective } \\
\text { Study }\end{array}$ & 12 & 2225 & NC & $\begin{array}{l}\text { Abbam \& } \\
\text { Ibrahim, 2018 }\end{array}$ \\
\hline 6 & 3 & 131 & $\begin{array}{l}\text { Retrospective } \\
\text { Study }\end{array}$ & 12.7 & 560 & NC & $\begin{array}{l}\text { Rilwan et } \\
\text { 2020 }\end{array}$ \\
\hline
\end{tabular}




\section{DISCUSSION}

Table 1 shows the established diagnostic reference levels (DRLs) for chest (CT) i.e. computed tomography scan in CTDI and DLP in the previous literature conducted in northern Nigeria, which presents that Joseph et al. (2017) have the highest CTDI value of $18 \mathrm{mGy}$, followed by Mary-ann et al. (2018) and Ernest et al. (2018) each with CTDI of 17mGy. Abdullahi et al. (2019) have the lowest CTDI of 9.9mGy with Kabir (2015) of 10mGy. Mary-ann et al. (2018) and Ernest et al. (2018) also score the highest dose length product (DLP) in the established diagnostic reference levels for chest (CT) scan, each with $735 \mathrm{mGy} . \mathrm{cm}$, while Kabir et al. (2016) record the lowest with 407mGy.cm DLP.

Table 2 presents the established diagnostic reference for abdominal computed tomography scan in different literature reviews in northern Nigeria. Mary-ann (2018) scores the highest CTDI of $20 \mathrm{mGy}$ with Joseph et al. (2017) of 19mGy, while Abbam \& Ibrahim (2018) record the lowest CTDI value of $12 \mathrm{mGy}$ and Rilwan et al. (2020), 12.7mGy. The highest DLP is recorded by Abbam \& Ibrahim (2018) with value 2225mGy.cm and Mary-ann et al. (2018), 1486mGy.cm; the lowest DLP is recorded by Rilwan et al. (2020) which is $560 \mathrm{mGy} . \mathrm{cm}$.

Table 3: Estimated Mean \pm SD, $25 \%$ and $75 \%$ Values of CTDI and DLP for Chest CT

\begin{tabular}{|l|l|lll|lr|rr|}
\hline $\begin{array}{l}\text { Centre } \\
\text { Number } \\
\text { Used }\end{array}$ & $\begin{array}{l}\text { Number } \\
\text { of } \\
\text { Patients } \\
\text { Used }\end{array}$ & CTDI & & Mean \pm SD & \multicolumn{2}{|c|}{ 25\% Percentile } & \multicolumn{2}{|c|}{$75 \%$ Percentile } \\
\hline 55 & 934 & $13.98 \pm 3.76$ & $600.7 \pm 153.73$ & 9.98 & 407 & 17.25 & 735 \\
\hline
\end{tabular}

Table 4: Estimated Mean \pm SD, $25 \%$ and $75 \%$ Values of CTDI and DLP for Abdomen CT

\begin{tabular}{|l|l|lr|lr|rr|}
\hline $\begin{array}{l}\text { Centre } \\
\text { Number } \\
\text { Used }\end{array}$ & $\begin{array}{l}\text { Number } \\
\text { of } \\
\text { Patients } \\
\text { Used }\end{array}$ & CTDI & Mean \pm SD & \multicolumn{2}{|c|}{ 25\% Percentile } & \multicolumn{2}{|c|}{$75 \%$ Percentile } \\
& & & DLP & CTDI & DLP & CTDI r & DLP \\
\hline 55 & 934 & $15.5 \pm 3.32$ & $1285.8 \pm 590.08$ & 12.53 & 707.75 & 19.25 & 1670.75 \\
\hline
\end{tabular}

Table 3 and table 4 present the estimated diagnostic reference levels for CT chest and abdomen examinations. In this review, it is recommended that the DRL should be set at the level of the third quartile in the dose distribution of the measured CTDIvol per series and DLP per examination. The third quartile value is chosen as an appropriate investigation level on the grounds that if $75 \%$ of the CT units can operate satisfactorily below this dose level, then the remaining $25 \%$ should be made aware of their considerably less than optimal performance. Operators of the units should be encouraged to adjust their radiographic protocols by lowering the $\mathrm{kV}$ and $\mathrm{mA}$ or increasing the slice thickness to bring their doses in line with the $75 \%$ majority. 
African Journal of Environment and Natural Science Research

ISSN: 2689-9434

Volume 4, Issue 2, 2021 (pp. 83-90)

www.abjournals.org

Table 5: Estimated DRLs for Chest CT scan with 75\% Percentile

\begin{tabular}{|c|c|cc|}
\hline Centre Number Used & Number of Patients Used & \multicolumn{2}{|c|}{ DRLs } \\
\hline 55 & 934 & 17.25 & 735 \\
\hline
\end{tabular}

Table 6: Estimated DRLs for Abdomen CT Scan with 75\% Percentile

\begin{tabular}{|c|c|cr|}
\hline Centre Number Used & Number of Patients Used & \multicolumn{2}{|c|}{ DRLs } \\
\hline 55 & 934 & 19.25 & DLP \\
\hline
\end{tabular}

Tables 5 and 6 present the estimated DRL for chest and abdomen CT examinations which show CTDIvol of $17.25 \mathrm{mGy}$ and DLP of $735 \mathrm{mGy} . \mathrm{cm}$ for chest and CTDIvol of $19.25 \mathrm{mGy}$ and DLP of $1670.75 \mathrm{mGy} . \mathrm{cm}$ for abdomen.

Table 7: Comparison of the Review DRL with International Value for CT chest

\begin{tabular}{|l|l|l|l|l|l|}
\hline $\begin{array}{l}\text { Dose } \\
\text { Quantities }\end{array}$ & $\begin{array}{l}\text { Reviewed } \\
\text { DRLs }\end{array}$ & $\begin{array}{l}\text { United States } \\
2015\end{array}$ & India 2014 & Greece 2015 & ICRP 2007 \\
\hline CTDIvol & 17.25 & 17 & 12 & 14.4 & 30 \\
\hline DLP & 735 & 610 & 456 & 481 & 650 \\
\hline
\end{tabular}

Table 7 presents the comparison of the reviewed DRLs for CT chest examination with recommended international values; the reviewed DRLs are greater than all the international values, including the DLP for ICRP 2007 publication. This shows that the scan parameters used in northern Nigeria need to be adjusted, and the researchers need to work tirelessly in bringing the idea that will be used in reducing the radiographic protocol.

Table 8: Comparison of the Review DRLs with International Value for Abdomen

\begin{tabular}{|l|l|l|l|l|l|}
\hline $\begin{array}{l}\text { Dose } \\
\text { Quantities }\end{array}$ & $\begin{array}{l}\text { Reviewed } \\
\text { DRLs }\end{array}$ & $\begin{array}{l}\text { United States } \\
2015\end{array}$ & India 2014 & Greece 2015 & ICPR 2007 \\
\hline CTDIvol & 19.25 & 17 & 16 & 16.3 & 35 \\
\hline DLP & 1670.75 & 860 & 482 & 758 & 780 \\
\hline
\end{tabular}

Table 8 presents the comparison of reviewed DRLs with recommended international values for abdominal CT examination, which shows that the reviewed DRLs values are above all international values excluding the CTDIvol of ICRP 2007 publication, but the reviewed DLP values are greater than any recommended value. Therefore, the reported doses and DRLs values are representatives of CT facilities and practices in northern Nigeria. Our findings provide a national benchmark for CT doses and should facilitate optimization strategies to reduce the dose burden from CT examinations across the region. 


\section{CONCLUSION}

There are very wide variations in doses for chest and abdominal CT examinations within and between radiological facilities in northern Nigeria. The 75th percentile CTDIvol dose values for these procedures are comparable to those reported international values, including the recommended ICRP 2007. However, the CTDIvol and DLP for this review are considerably higher. Technological and technical factors appear to be significant contributors to high doses and dose variations. Upgrade in CT technology, optimization of protocols including exposure and technical parameter selection should help reduce dose variations. Any examination with dose outliers above the 75th percentile urgently needs to explore as low as reasonably practicable dose protocols, whilst those with wide dose variations should consider standardizing protocols to narrow dose values.

\section{REFERENCES}

Abbam \& Ibrahim S, (2018) "Assessment of average radiation dose for abdominal computed tomography examination in Aminu Kano teaching hospital, Kano" Bayaro jounal of pure and applied science 11(2)1-8

Abdullah., A. (2009) "Establishing Dose Reference Level for CT Examination in Malaysia" Thesis submitted in fulfilment of the requirements for the degree of Master of Science University Sains Malaysia. Available at: http://www.eprints.usm.my.

Drouet., F. (2007) “The Diagnostic Reference Levels (DRLs) in Europe”. Available at: http://www.eu-alara..net

Ernest., U. E; Thomas., A; Judith., D. A; Owujekwe., C. E; Ali., M. A; Mohammed., A; Kudirat., A. A; David., O. O; Uche., H. C. (2018) "Diagnostic Reference Levels for common Computed Tomography (CT) examinations: results from the first Nigerian nationwide dose survey, Article in Journal of Radiological Protection”. DOI: 10.1088/1361-6498/aaaaf8

European Commission (1999) "Guidance on Diagnostic Reference Level (DRLs) for Medical Exposures. Radiation Protection 109” Available at: http://www.ec.europa.eu

Garba., I, (2014) "Computed Tomography Dose Index for Head CT in Northern Nigeria" Msc Thesis, Cape Peninsula University of Technology.

IAEA (2011) "Radiation Protection and Safety of Radiation Source: International Basic Safety Standards. General Safety Requirements Part 3 No. GSR Part 3 (Interim)". Available at: http://www-pub.iaea.org/p153 interim web.

ICRP (1991) "Publication 60, 1990 Recommendations of the International Commission on Radiological Protection" Annals, 21:1-3.

Joseph., D.Z; Christian., C.N; Mohammed., S.U; Ameh., P.O; Njoku., G, Malgwi., F.D, Moi., A. S \& Shem S.L (2017) "Establishment Of Local Diagnostic reference levels (DRLs) for radiography examinations in north eastern Nigeria". Science World Journal Vol 12(No 4) www.scienceworldjournal.org ISSN 1597-6343

Kabir., A.M, Schandorf C, Hasford F (2016) "Determination of Computed Tomography Diagnostic Reference Levels in North-Central Nigeria". The Pacific Journal of Science and Technology. 17(2):341-349.

Marry-ann., E.E; Rachel., I.O \& Akintayo., D.O (2018) "Patient dose Estimation using CTExpo software at two Hospitals in northern Nigeria" South.clin.ist.Euras. 29 (2)125-131 
NCRP (2009) "National Council on Radiological Protection Report 172 Pie Charts" Bethesda, MD 20814-3095.

Ogbole and Obed, (2014) "Radiation doses in computed Tomography: Need for for optimization and application of dose reference levels in Nigeria" West African Jol of Radiology. Vol: 21:1 p1-6.

Olowookere C.J, Babalola, I.A, Jibiri, N.N, Obed R.I, Bamidele, L., \& Ajetumobi, E.O., (2012). "A preliminary Radiation dose Audit in some Nigerian Hospitals: Need for National Diagnostic reference levels (NDRLs)". The pacific journal of science and technology. Vol: 13(1), Pg. 487-495.

Seabourn, J.T. (2010) "Radiation Dose Considerations in CT Imaging. Power Point Presentation" Available at: http://www.imirad.net/RADIATION

Treier, R., Aroua, A., Bochud, F., Samara, E., Verdun, F.R., Stuessi, A. Trueb, Ph.R. \& Zeller, W. (2009) "Diagnostic Reference Levels in Computed Tomography in Switzerland" IFMBE Proceedings 25/ III, pp. 146-149 